\title{
Research on the Opportunity Window Mechanism of Enterprise's Position Transition under the Embedded Context
}

\author{
-A Case Study of BYD
}

\author{
Zhang Xia \\ Department of Technical Economy and Management \\ Zhejiang Gongshang University \\ Hangzhou, Zhejiang, China \\ 1769408303@qq.com
}

\author{
Chen Xueguang \\ Department of Engineering Management \\ Zhejiang Gongshang University \\ Hangzhou, Zhejiang, China. \\ cxgbox@163.com
}

\begin{abstract}
This article takes BYD as an example to study the mechanism of the timing window of the enterprise's potential transition under the embedded scenario. Companies use their own within the international electric car industry network which close to the huge domestic market advantageous market position, seize the domestic consumption upgrade market timing window, through the integration of industrial chain resources, expanding production to improve enterprise's market potential; Companies use battery industry in the network manufacturing technical level cognitive lithium battery technology breakthrough time window, through the transplanted cells and mobile technology research and development experience, improve enterprise in the electric car industry technology. Network enterprise potential, therefore, this paper argues that industry by the market, the market potential, technical level and technical potential, enterprises in the industry network potential with time window is adaptive dynamic adjustment mechanism.
\end{abstract}

Keywords-Embeddedness; Industrial network; Potential; The window of opportunity

\section{INTRODUCTION}

Under the trend of globalization, enterprises not only face the competition of local enterprises but also face pressure from foreign enterprises, which makes the boundary of competition between enterprises become increasingly blurred. Compared with foreign enterprises, domestic high-tech enterprises have obvious gaps in development environment, technology level and their own enterprise development level. The low-level disadvantages of local companies which formed due to differences in technological accumulation and technological factor endowments, and in the context of network embedding, the transfer of competitive pressures to local companies is more direct, it also makes the transition from low to high levels of local enterprise network potential to a phased normal state. On the other hand, Chinese economy is standing an important stage of comprehensive transformation and upgrading. Many domestic high-tech enterprises have also been highly expected by the local government in the process of promoting industrial upgrading. They are required to play the role of the locomotives, occupy the commanding heights of the global industry, improve and expand the overall development and operation space of the local industry. With the process of economic globalization, local companies are gradually embedding into the global industrial network system, and with the help of certain "advantages of latecomer", they have started "learning competitions" with international technology-producing enterprises and gradually occupy the core position and get the knowledge and opportunities which they need more quickly within the industrial network. This article intends to take BYD's positional transition as an example, focusing on the analysis of how the inner dimensions of the corporate position and the interaction mechanism between position and windows of time.

\section{LiterATURE REVIEW}

\section{A. Enterprise potential research}

The concept of enterprise position derives from the theory of physical potential. In physics, an object has a certain potential energy comes form its position, and the conduction and diffusion in the world of all material or non-material are caused by a potential difference and always spread from high potential energy to low potential energy. Therefore, it has a certain potential energy, and thus has the ability to attract resources. Enterprises with relatively high positions have a strong appeal to resources, and the resources that they attract are optimized and integrated to form capabilities or resource advantages. Miao Zhenlin (2012) integrated Porter's theory, resource theory and capability theory. He believes that companies integrate resources in certain ways into specific enterprise scales and qualities, form specific market orientations, and adapt to the external environment which forming an enterprise position eventually [1].

The corporate position comes from the comprehensive strength of the enterprise, and it increases with the relative enhancement of the overall strength of the enterprise. It is a market height formed by the scale of enterprise resources, the integration of enterprise resources, and the external environment of the enterprise (market-oriented) interaction. In a particular network, the enterprise position is a relative position in the industrial chain not an absolute property of the enterprise, which has new capabilities that the position can

Under Perspective of embeddedness: Position-based potentials transition mechanism of local high-tech firms. 
attract and integrate resources, possessing the new resources that this position can attract and the new ability to integrate resources brings a kind of ability or a condition, that is, the structural position of the enterprise in the industrial network will in turn affect the position of the enterprise (Fig.1).

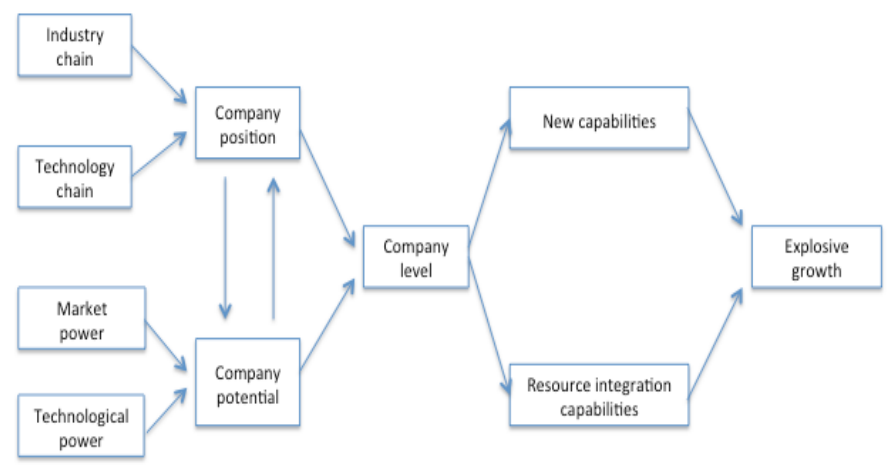

Fig. 1. Internal potential transformation of the enterprise

\section{B. Industrial network research}

In recent years, with the rapid growth and development of the "Internet + " new economy, the convection and cooperation between the economic resources of network organizations has been frequent, and the repetitive transactions among enterprises have prompted the formation and development of network organizations, and the corporate position in network organizations, which has become a key asset for building a sustainable competitive advantage for enterprises [2].

Chen Sijie (2017) believes that due to the division of labor in the industry and the formation of a pool-dependency relationship between cooperative networks, the complex relationships among various participants constitute a network structure, industrial networks in which different members control different resources and practical activities. In its well-known dynamic capabilities framework, Teece summarized the company's dynamic capabilities as three dimensions of process, potential, and path. The potential is the company's specialized assets, including information, knowledge, technology, brand, reputation, and key assets such as relationships with related stakeholders. In a network organization, the more scarce or specialized assets enterprise has, the higher position it own. The corporate position is based on industrial networks it is composed of "position" and "potentials". Positions generate capabilities, in turn; the increase or decrease of capabilities will affect the distance between the enterprise and the center of the network. Since the network location is the result of the establishment of relationships between network nodes, enterprises occupying good network locations have comparative advantages in knowledge acquisition, information integration, and resource dominance, and they have higher visibility and greater attraction for heterogeneity resources in the network.

\section{Research on embeddedness theory}

The theory of embeddedness has been proposed from the first concept and has a history of more than 70 years. Granovetter (1985) creatively reshaped the concept of embeddedness, based on Polanyi. He believes that the actors in the network are affected by the interrelationship between the network structure and the actors [3]. To better interpret embeddedness, Barber (1995) proposed that it needs to be placed in a complex social system, and any economic behavior is embedded in a complex social system. In embedded situation, economic behavior is carried out in a more complex and diverse environment under a procedural market in newer classical economics, involving more extensive and complex resources and relationships [4]. Uzzi used 23 clothing companies as the research object to explore the relationship between embeddedness and corporate performance [5]. It was found that there was an inverted U-shaped relationship between embeddedness and corporate performance. On the whole, the actors in the network are affected by the interrelationship between the network structure and the actors. They cannot be isolated and researched and analyzed in isolation. As a structural functional analysis framework, the network can be divided into relations and structures, which emphasized content and network structure respectively, both of them represent different degrees of abundance and high quality of resources.

\section{Time window study}

With regard to the study of the timing window, most scholars analyze this issue from the perspective of technological change. For example, when the window of opportunity was born on the appearance of a new technology track, as long as the window of opportunity is accurately grasped, it can pay a lower cost and more easily break through barriers to technology entry (Perez, Soete, 1988); the window of opportunity for technological leapfrogging often occurs when the chaos of new or old technology paradigm shifts or when the new paradigm emerges (Brezis, 1993; Wu Xiaobo, Li Zhengwei, 2002); There is a window of opportunity for different technological innovations at different stages of the industry's growth (Mao Jianqi, 2008). For innovation research, it is not enough only to study the technical track. The market dimension is also worthy of study. Based of the theory of technology trajectory, a new concept framework of "market track" driven by demand factors and channel factors has been constructed [6]. The diversity of the existing market trajectories and the destructiveness of new market trajectories have given rise to four kinds of timing windows: the track-orientation, the diversion-track, the rail-change, and the derailment [7].

More comprehensive view is that the combined effects of technology and the market accompany the opening of the timing window. Moreover, the timing of the opening and closing of the window is only due to the participation and entry of the company, otherwise the timing window is only a potential opportunity. Technology accumulation and technology transfer are the necessary conditions for opening the window of opportunity. Markets and customers are also important factors affecting the opening of the window of opportunity [8]. The emergence of the window of opportunity was the result of multiple factors such as technological changes, market changes, leading companies' "capability traps" and late-generation companies' endogenous capabilities [9]. If we can build a low-cost "environmental scanner" that connects home and abroad, and timely sense the external technology and market trends, we can help companies identify potential window of opportunity in time (Bessant, 2005). The timing window will not exist for a long time. Once this imbalanced 
phase is missed, the timing window will close and the opportunity will never return. In addition to identifying potential opportunities from the external environment and using them, there is a case where the subjective initiative is used to create opportunities (Zuo Zheng, 2009). When the opportunity to achieve a jump is not obvious, or misses the best opportunity for entry, some companies choose to take the initiative to create opportunities, and they tend to create many opportunities that are not existent at the same time than competitors (Bingham, Eisenhardt, 2011). The other is that companies are keenly aware of potential opportunities and are able to grasp fleet opportunities more quickly and effectively than competitors (Bingham, Haleblian, 2012). Grasping the window of opportunity enables the company to achieve rapid development.

\section{Research Methods and SAmple Selection}

\section{A. Research methods}

This study adopts a longitudinal single case study method, which mainly considers that the case study method is a relatively straightforward study of events in a realistic scenario, which is conducive to fully and objectively demonstrating the facts. In terms of material collection and exploratory law discovery, it is more flexible than the questionnaire method. In sample selection, following the principle of purposeful sampling, choose a company with sufficient specificity and typicality as a sample case. Therefore, this article selects BYD as the case study object after successful development from the battery foundry to the upgrade of its own brand automobile after more than ten years of development. Through the single case study, we capture and trace the phenomena and problems that have arisen in the development of enterprises, and propose a mechanism model of the relationship between the corporate position and the timing window (Fig. 2).

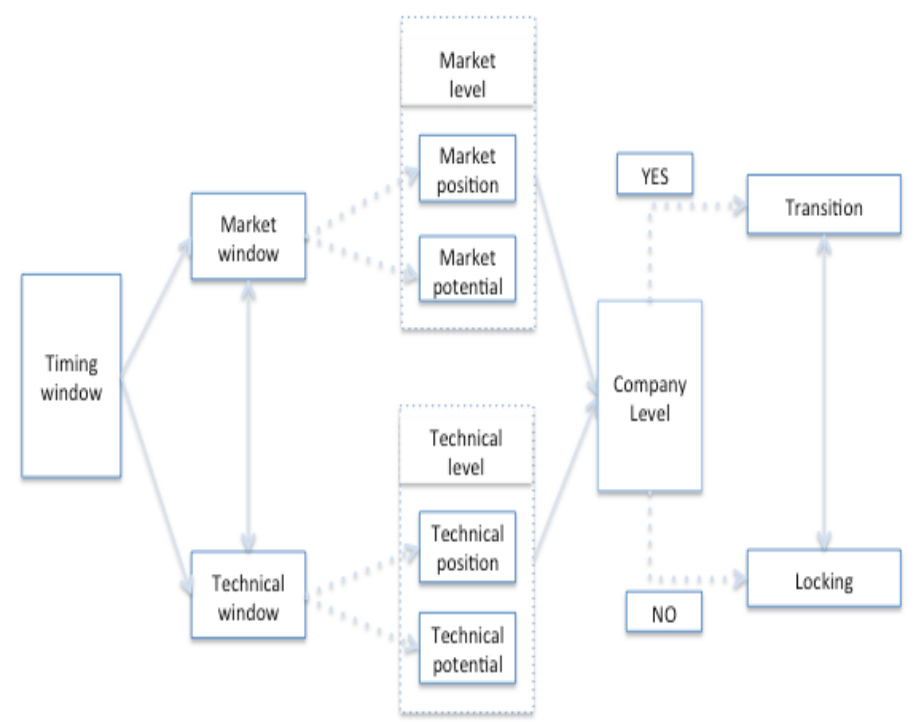

Fig. 2. The mechanism of enterprise potential and timing window

\section{B. Sample selection}

Founded in 1995, BYD was listed on the Hong Kong main board on July 31, 2002. The company is headquartered in Shenzhen and is a high-tech private enterprise with IT, automotive, and new energy industries. BYD has established nine production bases in Guangdong, Beijing, Shaanxi, Shanghai, Tianjin and other places, with a total area of nearly 7 million square meters, and has branch offices or offices in the United States, Europe, Japan and other countries. The total number of companies reaches 200,000 (TABLE I).

TABLE I. DEVELOPMENT HIST ORY OF BYD COMPANY LIMITED

\begin{tabular}{|c|l|}
\hline Time & \multicolumn{1}{|c|}{ Events } \\
\hline In 1995 & BYD is established. \\
\hline In 2002 & $\begin{array}{l}\text { The company is listed on the Hong Kong Main Board and is headquartered in } \\
\text { Shenzhen, Guangdong. }\end{array}$ \\
\hline In 2003 & $\begin{array}{l}\text { The acquisition of Xi'an Qinchuan Automobile, officially entered the automobile } \\
\text { manufacturing and sales. }\end{array}$ \\
\hline In 2008 & $\begin{array}{l}\text { BYD acquired Ningbo Zhongwei for nearly RMB 200 million, accelerating the pace } \\
\text { of commercialization of electric vehicles. In December of the same year, the world's } \\
\text { first dual-mode electric vehicle that does not rely on professional charging stations } \\
\text { was officially launched in Shenzhen. }\end{array}$ \\
\hline In 2009 & $\begin{array}{l}\text { BYD plans to launch pure electric vehicles and acquires Sanxiang passenger cars } \\
\text { from the United States. There is another important sequence in the new energy } \\
\text { automotive sector: bus products with huge market potential. }\end{array}$ \\
\hline In 2010 & $\begin{array}{l}\text { BYD, in cooperation with Daimler, plans to develop electric vehicles in combination } \\
\text { with BYD's experience in car batteries and drive motors and Daimler's experience in } \\
\text { traditional car manufacturing, and it is even possible to establish a full-fledged joint } \\
\text { venture Company. }\end{array}$ \\
\hline In 2012 & $\begin{array}{l}\text { BYD's new model, Speedy, is officially listed, and its automotive business accounts } \\
\text { for more than half of BYD. }\end{array}$ \\
\hline In 2016 & $\begin{array}{l}\text { BYD's total operating income reached } 103.975 \text { billion yuan, up 29.95\% year-on-year, } \\
\text { and net profit reached } 5.044 \text { billion yuan, up 78.63\% year-on-year. }\end{array}$ \\
\hline In 2017 & $\begin{array}{l}\text { BYD sales of } 416,000 \text { vehicles, of which new energy vehicles sales of 113,000, } \\
\text { ranking second in the industry. }\end{array}$ \\
\hline
\end{tabular}

\section{CASE ANALYSIS}

\section{A. The market place combines market timing window to increase market potential}

The company uses its own market position in the international electric vehicle industry network,which approached the domestic huge market, seizes the opportunity window of domestic consumption upgrade, and enhances the market potential of the enterprise by integrating the industrial chain resources and expanding production and sales.

\section{1) Favorable market position}

\section{a) Close to the market center}

As people's living standards have increased, the consumption structure has also undergone tremendous changes,automobile consumption has gradually become a trend and the domestic market has great demand. At the beginning of the 21st century, China's automobile production and sales surpassed the United States for the first time and becoming the world's largest automobile production and sales volume (Fig.3). 


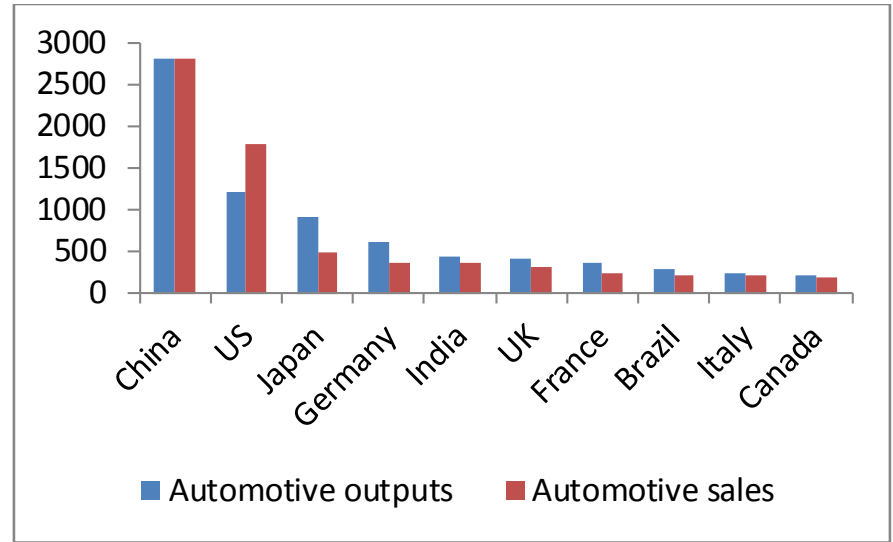

Fig. 3. Global auto sales in 2016 (unit: 10,000 vehicles)

According to the theory of market centrality, businesses will have the advantages of information and channel cost, which closed to the market center. Located at the forefront of the Pearl River Delta, Shenzhen is a national economic center. BYD, which is headquartered in Shenzhen, is located in the huge market of China, occupying a central position. Compared with other companies, it has more advantages of market and lays a solid foundation for the later development of the automobile industry.

The cognitive dimensions of individual traits based on social network theory, with the same cultural background, members in a unified social network, have similar consumption concepts and preferences. As a domestic company, BYD has a more convenient advantage than Tesla and other foreign companies, that is, BYD and consumers have experienced common social changes and can respond to this in a timely manner by launching products that cater to the market and consumers.

According to social network analysis theory, BYD and its consumers, as members of a social network, have the same structural attributes. BYD holds the current market conditions and consumer demand, subconsciously guide consumers' consumer behavior.

\section{b) Structural holes}

Burt believes that in social networks, third parties that connects other individuals have information and control advantages. Therefore, individuals in organizations and societies must strive to occupy third-party positions in structural holes. BYD plays exactly the structural hole between domestic market and foreign market in automotive industry networks. BYD has won the market with a cooperative investment, which has achieved remarkable results. In 2012, BYD received an order for 1000 electric buses from Changsha Public Transport Group and invested more than RMB 3 billion to establish a new energy automobile production base; successively established production sites in Xi'an, Changsha, Tianjin, Shenzhen, and Wuhan; Abroad, BYD cooperates with Nokia, Motorola, Mercedes-Benz, Intel and other international start-up companies to expand their market share in foreign markets and increase their visibility. In 2016, BYD announced that it invested USD 24.4 million to build an electric bus plant in Komámlon, Hungary, and officially entered the European market. While participating in the development of the domestic automobile market, BYD is also in the midst of the international automobile market. It is an important medium for domestic cars to go international.

\section{2) Market timing window}

With the development of our country's economy and the increase of residents' income, the automobile industry in China has developed rapidly since 2002 when it joined the WTO. Due to the continuous increase of the base number, the automotive industry entered a period of stable growth. Until 2016, supported by policies, the growth rate of automobiles reached double-digit again, which was $13.95 \%$ higher than the same period of last year. In the first half of 2017, due to the influence of the impulse at the end of 2016, the growth rate was reduced to $3.81 \%$, and the annual growth rate is expected to be $3 \%$ to $4 \%$ (Fig.4).

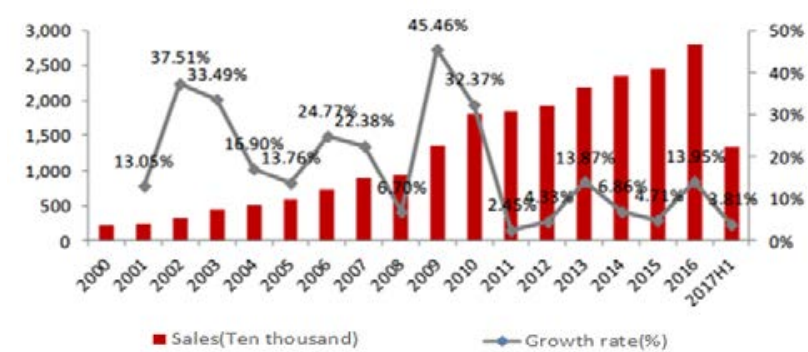

Fig. 4. Auto sales in China from 2000 to 2017

From the above figure, we can see that the time window of the market appeared in 2008, and the growth rate of car sales in this year reached $45.46 \%$. Subsequently, the country introduced a corresponding new energy vehicle subsidy policy, program support for automotive companies to develop new energy vehicles. In this context, China's demand for new energy vehicles is more and more urgent. BYD's development of new energy vehicles has preconditions, and it also provides an important strategic opportunity for the leap-forward development of China's automobile industry.

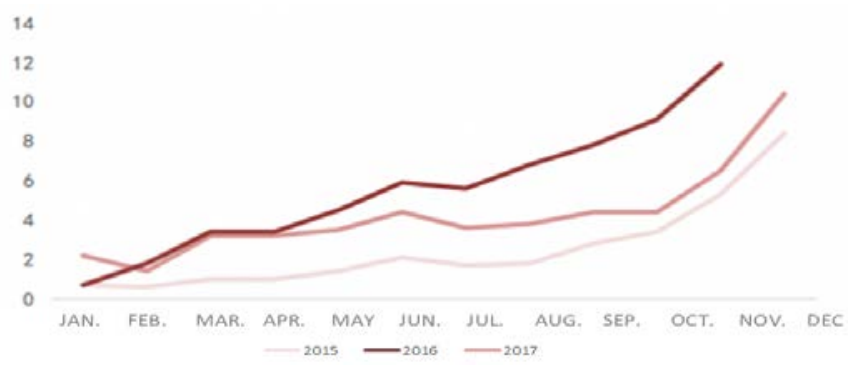

Fig. 5. Chinese new energy vehicle sales in the past three years

From the data of 2015-2017, the overall market for new energy vehicles is still expanding, and the demand for new energy vehicles is increasing. BYD seized the window of opportunity brought by the upgrading of auto consumption, copied the model and resources of battery production and mobile phone OEM, entered the automotive industry with the ultimate goal of new energy vehicles, and made a transition to a high level. In 2016, BYD's operating revenue exceeded RMB 100 billion to reach RMB 1.034 billion, an increase of $29.32 \%$ 
year-on-year; total profit was RMB 6.568 billion, an increase of $73.08 \%$ year-on-year.

\section{3) Enhance market potential}

The market potential is the ability of companies to control the prices of their products. Many scholars have given similar definitions of market potential in their respective studies. Coughlan (2003) believes that the market potential is the potential influence or power of the company in the market. This article is based on the "SCP paradigm" proposed by the Harvard School of Industry (Bain, 1959; Scherer, 1970). The market structure will form a kind of market power. Market forces will determine the company's behavior and then determine the company's profitability. That is, the greater the market share of the company, the stronger the profitability, indicating that the company has a higher market power.

BYD uses its favorable market position in Chinese huge market, which is close to electric vehicle industry network, to seize the sudden increase in domestic demand for new energy vehicles and the window of opportunity brought by consumption upgrades. Established nine production bases to expand production and sales, and increase market share.

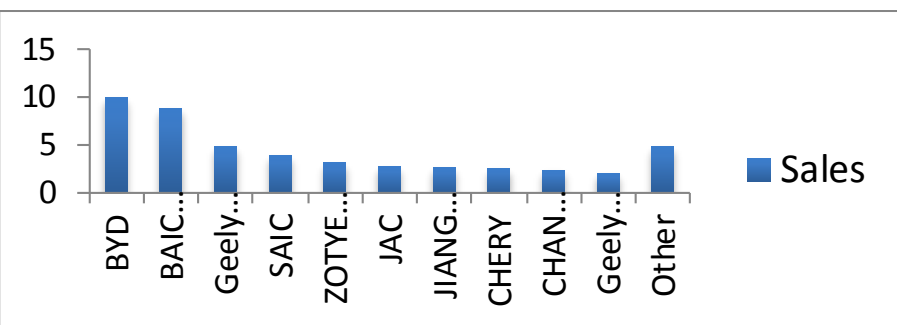

Fig. 6. Sales ranking of new energy passenger vehicles in January and November 2017 (unit: 10,000 vehicles)

The data shows that in 2017 BYD new energy vehicles sold nearly 100,000 vehicles, a substantial increase of $69.85 \%$ year on year, the world's sales volume is the number one. Among them, domestic revenue accounted for 92.55\%; BYD's international market revenue reached $7.45 \%$. In the global market share of up to $13 \%$, total revenue of 7.705 billion yuan, BYD new energy vehicles continue to lead the global market.

\section{B. Technology position combined with technology opportunity window to enhance technology potential}

BYD was initially on the edge of the automotive industry network, the technology position was very marginal. Enterprises use the center of the technical network for battery $\mathrm{R} \& \mathrm{D}$ and manufacturing in the industrial chain, increase investment in $\mathrm{R} \& \mathrm{D}$, and sense the timing of the emergence of new technologies for the new energy vehicle in the electric vehicle industry. Through the introduction of advanced battery manufacturing technology from Japan and the United States, it mastered the core technologies for lithium battery manufacturing, embedded in the electric vehicle manufacturing technology network, and gradually increased its technological potential.

\section{1) Technical position}

BYD accumulated a wealth of technology and R\&D experience in the previous battery manufacturing. It occupied a core position in the industry network of the battery industry, produced BYD's unique iron batteries, and used iron batteries as the core weapon for the future new energy automobile war. BYD, based on its favorable technical position in the battery industry network, has entered the automobile industry network, ingeniously combining its own core technologies in batteries with the research and development of electric vehicles, and has a leading electric vehicle product line.

\section{a) Intermediaryposition}

BYD has just imitated the battery R\&D technology of foreign first-time companies, and later independently researched and developed nickel-cadmium batteries and lithium batteries. In this process, it has accumulated rich experience in technology and $R \& D$, and has occupied a core position in the battery R\&D technology network. At the beginning of entering the automotive market, BYD can be said to have zero experience in automobile manufacturing and is at the forefront of the automotive manufacturing technology network. BYD's automobile manufacturing technology has also experienced BYD brand cars that have imitated and imported domestic and foreign start-up companies, as well as independent innovation and research and development. BYD occupied the intermediary position of the battery $R \& D$ technology network and the electric vehicle manufacturing technology network. The core technology of its battery R\&D has become the basis for the development of power batteries for future electric vehicles.

\section{b) Centre position}

BYD took the intermediary position of the two technology networks of the battery $R \& D$ technology network and the electric vehicle manufacturing technology network. Through technological introduction, reverse $R \& D$, and independent $\mathrm{R} \& \mathrm{D}$, the technology innovation capability and production capacity have rapidly increased. The ability of technological innovation is the support of the company's overall technological capabilities. It can increase the production capacity and effectively convert the new knowledge acquired by the company into innovative results. Through this continuous R \& D model of "absorption-digestion-independent innovation", BYD gradually increases its own technological position in the electric vehicle R\&D technology network and takes a central position in the electric vehicle manufacturing technology network.

\section{2) Technical opportunity window}

Over 130 years of development of the world's automotive industry, core patented technologies have been dominated and monopolized by international giants. In 1993, Japan, the world's largest battery manufacturer, announced that it would abandon the production of nickel-cadmium batteries. BYD seized the opportunity to launch nickel-cadmium batteries, created its own "manpower line," and turned technology-intensive into labor-intensive. In 1997, BYD invested a lot of money in research and development of lithium batteries. In September 2000, BYD became Motorola's first lithium-ion battery supplier in China, breaking the monopoly 
position of Japanese companies for big brand mobile phone battery suppliers. Subsequently BYD entered the supplier system of a series of mainstream brands such as Nokia and Ericsson.

At the beginning of the 21st century, China's automobile sales volume grew rapidly, and oil demand increased significantly. Rapid industrialization led to serious pollution and significant increase in greenhouse gas emissions. It is imperative to develop energy-saving and environmentally friendly new energy vehicles. Three-cell lithium battery technology has become mainstream, and the automotive technology track has shifted from traditional fuel-powered automotive technologies to new energy technologies. BYD has realized this when it first entered the automotive industry. The company took advantage of this technology window, based on traditional fuel vehicles, and relied on years of battery R\&D technology to develop electric vehicles. Through continuous R\&D and experimentation, BYD's unique iron batteries were produced.

\section{3) Improve the technical potential}

The technological potential is that enterprises have the ability to innovate in technology, and technological innovation can enhance the company's potential capabilities, can form certain competitive advantages for other companies, and lay a solid foundation for the continued development and expansion of the company (Du Yong, 2014). For its measurement, there is currently no universally recognized indicator system in the theoretical community (Zeng Ping, 2013). Some scholars such as Hansen (1991) and Feng Genfu (2008) measured the level of technological innovation of enterprises with innovation inputs such as R\&D expenditures and sales ratios, and per capita R\&D expenditures. Other scholars such as Ahuja (2000) and Chen Jin (2007) measured the level of technological innovation of enterprises by the results of innovation, that is, the output of innovation, such as the number of patents applied, the rate of new product output, and the number of new products. Based on the perspective of the innovation process, combined with existing research results, this paper measures the technological potential of the company from the perspective of the technological innovation output (patent case).

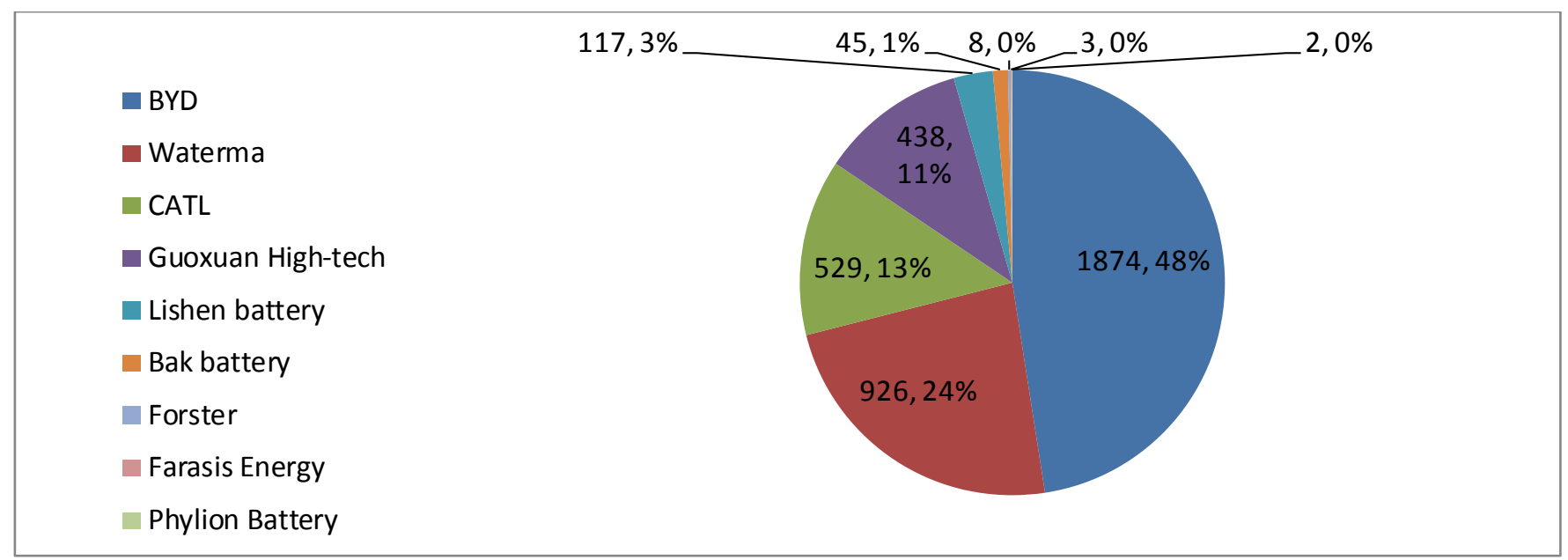

Fig. 7. The number of patents of 10 large battery enterprises in 2017 (unit: item)

BYD has a wide range of businesses and the number of patents is firmly at the top of the list. In 2017, BYD has issued a total of 1,874 patents, including 526 utility model patents, 405 invention authorizations, 836 invention announcements, and 107 exterior designs. BYD's core technology in the field of batteries has gradually risen from the edge of the automotive industry network to the leader in the new energy automotive industry. From January to November 2017, the statistical results of the power battery installed capacity were released. Among the total amount of 24.56 GWh, BYD accounted for $75.5 \%$ of the total, and topped the list with 1,874 patents (Fig. 7).

BYD entered the automotive industry at the beginning of its efforts to cultivate independent innovation capabilities, learn and imitate the advanced automotive products in the industry, and its technological innovation capability has continued to improve. It has mastered the core technologies for $R \& D$ and manufacturing of electric vehicles and has become the vanguard of domestic automotive new energy technologies.

\section{SUMMARY}

Throughout the development of BYD for more than 20 years, it can be roughly divided into three periods. It seizes the market and technological timing window and combines the potential of the company itself in the battery industry and the electric vehicle industry network to complete two potential shifts. BYD started from the OEM production of mobile phone batteries to the automotive industry, independently developed new energy vehicles, and became a company with its own brand. Based on the world's leading battery development technology, BYD entered the automotive industry and broke through the R\&D path of lead-acid batteries and lithium batteries followed in the development of traditional car batteries, and launched BYD's unique iron battery. BYD's F3 vehicle GPS satellite positioning system is fully self-developed, it masters the core mold manufacturing technology of the vehicle manufacturing, solves the key battery technology problems in the field of electric vehicles, and iron battery technology has also attracted many international giants to 
cooperate with them. At this point, BYD has become a leader in China's new energy vehicles.

\section{REFERENCES}

[1] Miao Zhenlin, Investment Policy Based on the Industrial Clusters, Forum on Science and Technology in China, vol.4,pp50-53, 2012. (In Chinese)

[2] Zhang Baocang, Renhao, Haobin. Research on the driving factors, classification mode and transformation path of enterprise potential [J]. Science and technology Management studies, 2017 (05). (In Chinese)

[3] Granovetter, m. Economic Action and Social Structure: The Problem of Embeddedness [J]. American Journal of Sociology, vol. 91(3), pp481-510, 1985.

[4] Dacin $M ~ T$, Ventresca $M$ J, Beal B D. The embeddedness of Organisation: dialogue directions [J]. Journal of Management, 1999,25:317-356.
[5] Uzzi B. Social structure and competition in interfirm networks: The paradox of embeddedness [J]. Administrative Science Quarterly, pp42-67, 1997.

[6] Dosi G,Faillo M,Marengo L. Organizational capabilities, patterns of knowledge accumulation and governance structures in business firms: an introduction[J].Organization Studies, 2008,29( 8-9):1165-1185.

[7] Xiong Hongru. From technical track to market track: Based on the chasing opportunity perspective [J]. Innovation and Entrepreneurship Management, pp102-112, 2012. (In Chinese)

[8] Cai Qionghua, Si Chunlin, Zhao Mingjian, Research on Enterprise Technology Leapfrogging Time Based on Breakthrough Technology Innovation [J]. Scientific Management Research, vol. 23(2), pp15-19, 2005. (In Chinese)

[9] Xu Yusen, Yu Di, Xu Nana. Research on the catch-up of innovation based on timing window in the fast-changing market environment -- A case study of HTC Company [J]. (In Chinese) 